\title{
Social Fear Conditioning: A Novel and Specific Animal Model to Study Social Anxiety Disorder
}

\author{
Iulia Toth', Inga D Neumann' and David A Slattery*,' \\ 'Department of Behavioral and Molecular Neurobiology, Faculty of Biology and Preclinical Medicine, University of Regensburg, Regensburg, \\ Germany
}

\begin{abstract}
Social anxiety disorder (SAD) is a major health concern with high lifetime prevalence. The current medication is rather unspecific and, despite considerable efforts, its efficacy is still unsatisfactory. However, there are no appropriate and specific animal models available to study the underlying etiology of the disorder. Therefore, we aimed to establish a model of specific social fear in mice and use this social fear conditioning (SFC) model to assess the therapeutic efficacy of the benzodiazepine diazepam and of the antidepressant paroxetine; treatments currently used for SAD patients. We show that by administering electric foot shocks ( $2-5,1 \mathrm{~s}, 0.7 \mathrm{~mA})$ during the investigation of a con-specific, the investigation of unfamiliar con-specifics was reduced for both the short- and long-term, indicating lasting social fear. The induced fear was specific to social stimuli and did not lead to other behavioral alterations, such as fear of novelty, general anxiety, depression, and impaired locomotion. We show that social fear was dose-dependently reversed by acute diazepam, at doses that were not anxiolytic in a non-social context, such as the elevated plus maze. Finally, we show that chronic paroxetine treatment reversed social fear. All in all, we demonstrated robust social fear after exposure to SFC in mice, which was reversed with both acute benzodiazepine and chronic antidepressant treatment. We propose the SFC model as an appropriate animal model to identify the underlying etiology of SAD and possible novel treatment approaches.

Neuropsychopharmacology (2012) 37, 1433-1443; doi:I0.1038/npp.20 I I.329; published online II January 2012
\end{abstract}

Keywords: social investigation; object investigation; novelty; sedation; benzodiazepines; antidepressants.

\section{INTRODUCTION}

Social anxiety disorder (SAD), often referred to as social phobia, is characterized by persistent fear and avoidance of social situations. Epidemiologically, SAD is the third most common psychiatric disorder, with a 12-month and lifetime prevalence of $6.8 \%$ and $12.1 \%$, respectively (Kessler et al, $2005 a, b)$. For diagnostic purposes, SAD has been divided in two subtypes: specific and generalized SAD. The specific form refers to the fear and avoidance of a particular social situation and includes performance anxiety (eg, fear of giving a public speech), interaction anxiety (fear of social interaction and observation situations), and fear of showing anxiety symptoms (Bögels et al, 2010). Patients with generalized SAD are more impaired as they fear and avoid a wide range of social situations (den Boer, 1997; Kessler et al, 1998; Ruipérez et al, 2002). This avoidant behavior has an important role in the maintenance of SAD and prevents

*Correspondence: Dr DA Slattery, Department of Behavioral and Molecular Neurobiology, Faculty of Biology and Preclinical Medicine, University of Regensburg, Universitaetsstrasse 31, Regensburg 93053, Germany. Tel: + 490941943 3076, Fax: + 490941943 3052,

E-mail: david.slattery@biologie.uni-regensburg.de

Received 2I September 201।; revised II December 201 I; accepted 12 December 2011 the reversal of fear in social situations (American Psychiatric Association, 1994; Stangier et al, 2006).

At present, SAD treatment consists of cognitive-behavioral therapy (CBT) (Gould et al, 1997; Fedoroff and Taylor, 2001), which leads to gradual fear extinction, ie, a decline in the fear response as a result of repeated exposure to the feared situation, and is often combined with medication originally designed for depression or generalized anxiety, such as antidepressants, $\beta$-blockers, and benzodiazepines. However, a high percentage of SAD patients fail to respond to the available treatment options, or achieve only partial remission of symptoms, with antidepressants providing the best response rates (Liebowitz et al, 1992; Baldwin et al, 1999; Van Ameringen et al, 2001). Given the high prevalence and unsatisfactory treatment options for SAD, a better understanding of the etiology and underlying neurobiological mechanisms of social fear, particularly extinction of social fear, is urgently needed. This, in turn, might provide important information for the development of more specific medication and an improved treatment outcome for SAD patients.

However, there are currently no appropriate animal models available to study the disorder. Social anxiety/avoidance is presently induced using a number of paradigms, including the social defeat paradigm- used both acutely and chronically (for reviews see Huhman, 2006; Yan et al, 2010), 
and foot-shock exposure (Haller and Bakos, 2002; Louvart et al, 2005; Mikics et al, 2008a). However, these paradigms are rather unspecific with respect to the behavioral alterations they induce, as increased general anxiety, depression, and impaired locomotion were found to accompany the social avoidance (Denmark et al, 2010; Hollis et al, 2010).

Therefore, we aimed to establish a novel and specific animal model of SAD using the social fear conditioning (SFC) paradigm, and use this model to assess the therapeutic efficacy of diazepam and paroxetine, currently used for SAD patients. The SAD-like phenotype was induced in naïve mice by punishing them when investigating an unfamiliar conspecific. Mice were conditioned to associate a shock-induced pain with the investigation of a social stimulus and, therefore, avoid social stimuli. The conditioned social fear is specific to several social stimuli, long-lasting and not accompanied by changes in general anxiety, depressive-related behavior, and locomotion. The social fearful phenotype was dose-dependently reversed by acute diazepam, at a dose that was not anxiolytic in a non-social context, ie, the elevated plus maze (EPM). Furthermore, chronic antidepressant treatment also reversed social fear, validating the SFC model.

\section{MATERIALS AND METHODS}

\section{Animals}

Male CD1 mice (Charles River, Sulzfeld, Germany) weighing $30-35 \mathrm{~g}$ were individually housed in polycarbonate cages $(16 \times 22 \times 14 \mathrm{~cm})$ for 1 week before experiments started, and remained isolated throughout. Isolation was shown to increase social motivation (Niesink and Van Ree, 1982) and prevent the attenuation of behavioral effects of stressors observed in group-housed mice (Ruis et al, 1999; Cherng et al, 2010). Mice were transferred to observation cages $(30 \times 23 \times 36 \mathrm{~cm}) 3$ days before experiments started. Ageand weight-matched male CD1 mice were used as social stimuli.

Mice were maintained under standard laboratory conditions (12:12 light/dark cycle, lights on at 0600 hours, $22^{\circ} \mathrm{C}$, $60 \%$ humidity, food and water ad libitum). Experiments were performed during the light phase, between 0800 and 1200 hours, in accordance with the Guide for the Care and Use of Laboratory Animals of the Government of Oberpfalz and the guidelines of the NIH.

\section{SFC Paradigm}

On day 1 , mice were conditioned for social fear, whereas on days 2 and 3 or 15 and 16, social investigation was assessed as readout of short- and long-term social fear and fear extinction.

SFC was performed with a computerized fear conditioning system (TSE System $\mathrm{GmbH}$, Bad Homburg, Germany). The conditioning chamber consisted of a transparent Perspex box $(45 \times 22 \times 40 \mathrm{~cm})$ enclosed in a wooden chamber to reduce external noise and visual stimulation. The floor consisted of a removable stainless steel grid connected to a shock delivery unit used for manual application of foot shocks. A video camera at the top of the chamber enabled video recording.
SFC (day 1). Mice were placed in the conditioning chamber and, after a 30-s adaptation period, an empty wire mesh cage $(7 \times 7 \times 6 \mathrm{~cm})$ was placed as a non-social stimulus near one of the short walls. Mice were allowed to investigate the non-social stimulus for $3 \mathrm{~min}$, before it was replaced by an identical cage containing an unfamiliar male mouse. Unconditioned mice were allowed to investigate the social stimulus for $3 \mathrm{~min}$. Conditioned mice were given a $1-\mathrm{s}$ electric foot shock $(0.7 \mathrm{~mA}$, pulsed current) each time they investigated the social stimulus, defined by direct contact with the mouse. Mice received between 2 and 5 foot shocks, with a variable inter-shock interval, depending on when direct social contact was made. The first social contact and foot shock occurred within 15-30 s. Mice were returned to their home cage when no further social contact was made for 2 min, meaning that conditioned mice spent between 3 and $6 \mathrm{~min}$ in the conditioning chamber while the social stimulus was present. The time mice spent investigating the non-social stimulus, as a pre-conditioning measure of nonsocial anxiety, was analyzed using the JWatcher program (V 1.0, Macquarie University and UCLA).

Extinction (day 2 or 15). To investigate whether conditioned mice displayed social fear and whether this fear could be extinguished, social investigation was assessed in the home cage 1 or 15 days after SFC for short-term and long-term social fear, respectively. In detail, extinction consisted of exposing the mice to three empty cages identical to the cage used during day 1 (non-social stimuli) to assess non-social investigation. Mice were then exposed to six unfamiliar male mice enclosed in wire mesh cages (social stimuli) to assess social investigation. Each stimulus was placed near a short wall of the home cage and presented for $3 \mathrm{~min}$, with a 3-min inter-exposure interval. Reduced social investigation and aversive responses toward the social stimuli, such as freezing, stretched approaches, and defensive burying indicated social fear and successful conditioning of social fear. As the empty cage elicited a fear response in conditioned mice, an empty cage was placed over night in the home cage to extinguish the fear of the cage.

Extinction recall (day 3 or 16). To investigate whether repeated exposure to social stimuli during extinction leads to a complete reversal of social fear, social investigation was assessed in the home cage 1 day after extinction. Extinction recall consisted of exposing the mice to six unfamiliar social stimuli for $3 \mathrm{~min}$, with a 3 -min interexposure interval.

\section{Specificity of the Induced Social Fear}

One day after SFC, we performed the EPM and the forced swim test (FST) to assess general anxiety-related and depressive-like behavior, respectively (Lister, 1987; Pellow et al, 1985; Slattery et al, 2005). Further, we assessed home cage locomotor activity as described previously (Reber et al, 2007; Slattery et al, 2011; for experimental details see Supplementary Methods). Moreover, we assessed the effects of SFC on novel object investigation, and the effects of foot shocks on social fear. 
Novel object investigation. Novel object and social investigation were assessed in the home cage 1 day after SFC to differentiate between fear of novelty and social fear. Mice were exposed to three non-social stimuli, three cages containing a white ball (novel object stimuli, size and color matched to the social stimuli), and three unfamiliar social stimuli. Each stimulus was presented for $3 \mathrm{~min}$, with a 3-min inter-exposure interval.

Electric foot-shock exposure. To assess the effects of footshock exposure in the absence of a social stimulus on social fear, mice were placed in the empty conditioning chamber and, after a 30-s adaptation period, received five electric foot shocks $(1 \mathrm{~s}, 0.7 \mathrm{~mA}$, pulsed current, ie, the maximum number received during SFC), with a 2-min inter-shock interval. Mice were returned to their home cage $2 \mathrm{~min}$ after the last foot shock. An empty cage was placed in their home cage over night to allow for comparable behavioral effects with SFC. One day later, social investigation was assessed during extinction.

Drugs. Diazepam (Ratiopharm $\mathrm{GmbH}$, Germany) was freshly dissolved in saline and administered intraperitoneally (i.p.) at a volume of $5 \mathrm{ml} / \mathrm{kg}$ and doses between 0.5 and $1.25 \mathrm{mg} / \mathrm{kg}$. The highest doses were chosen based on previous studies (Corbett et al, 1993; Dalvi and Rodgers, 1996; Stachowicz et al. 2008).

Paroxetine (Bayer Schering, Germany) was administered over 14 days via the drinking water at a dose of $10 \mathrm{mg} / \mathrm{kg} /$ day. The paroxetine dose was chosen based on previous studies (Da-Rocha et al, 1997; Hascoët et al, 2000a, b; Massé et al, 2005; Elizalde et al, 2008; Thoeringer et al, 2010).

\section{Experimental design}

Effects of SFC on Short- and Long-Term Social Fear. Initial experiments were designed to characterize the effects of SFC on short- and long-term social fear. Therefore, separate groups of mice were subjected to SFC and social investigation was assessed 1 or 15 days later during extinction ( $n=13$ per group for short- and $n=9$ per group for long-term effects). Extinction recall was measured 1 day later.

Specificity of the Induced Social Fear. To verify the specificity of the induced social fear, separate groups of mice were subjected to general anxiety (EPM; $n=8$ per group), depressive-like behavior (FST; $n=8$ per group), home cage locomotion ( $n=7$ per group), or novel object investigation ( $n=8$ per group) testing 1 day after SFC. Another group of mice was exposed to electric foot shocks in the absence of the social stimulus, and social investigation was assessed 1 day later during extinction $(n=8$ per group).

Reversal of Short- and Long-Term Social Fear by Acute Diazepam and Chronic Paroxetine Treatment, Respectively. To determine whether the effects of SFC on short- and long-term social fear could be reversed by medication used for SAD patients, we assessed the effects of diazepam and paroxetine, respectively. Mice $(n=10$ per group) were subjected to SFC. The following day, $30 \mathrm{~min}$ before extinction, mice were injected i.p. either with vehicle ( $5 \mathrm{ml} / \mathrm{kg}$ saline) or with diazepam $(0.5,0.75,1.0$, and $1.25 \mathrm{mg} / \mathrm{kg}$ ). Extinction recall was measured 1 day later. To determine whether diazepam has anxiolytic effects in a nonsocial context at doses used to reverse social fear, naïve mice were injected i.p. either with vehicle $(5 \mathrm{ml} / \mathrm{kg}$ saline) or with diazepam $(0.5,0.75,1.0$, and $1.25 \mathrm{mg} / \mathrm{kg}) 30 \mathrm{~min}$ before EPM testing. In a separate group of mice ( $n=8$ per group), social investigation was assessed 15 days after SFC. Paroxetine $(10 \mathrm{mg} / \mathrm{kg} / \mathrm{day})$ was administered chronically via the drinking water over 14 days, starting 1 day after SFC to prevent possible confounding effects on fear memory consolidation. Extinction recall was measured 1 day later.

Statistical Analysis. For statistical analysis PASW/SPSS (Version 17) was used. Data were analyzed by Student's $t$-tests, one-way or two-way ANOVA for repeated measures, followed by a Bonferroni's post-hoc analysis whenever appropriate. Statistical significance was set at $p<0.05$. Overall statistics are shown in Table 1.

\section{RESULTS}

\section{Effects of SFC on Short- and Long-Term Social Fear}

Short-term social fear. Mice showed similar pre-conditioning non-social anxiety (Figure 1a, Table 1). One day after SFC, conditioned mice showed similar non-social investigation, but reduced social investigation $(p<0.05$, Figure $1 \mathrm{~b})$ compared with unconditioned mice. No difference between the mice was found during extinction recall (Figure 1c).

Long-term social fear. Mice showed similar pre-conditioning non-social anxiety (Figure 2a, Table 1 ). Fifteen days after SFC, conditioned mice showed similar non-social investigation, but reduced social investigation $(p<0.05$; Figure $2 \mathrm{~b}$ ) compared with unconditioned mice. In contrast to short-term social fear, conditioned mice still showed reduced social investigation during extinction recall $(p<0.05$, Figure 2c).

\section{Specificity of the Induced Social Fear}

No effect of SFC on general anxiety, depressive-like behavior, and home cage locomotion. Conditioned mice showed no changes in general anxiety (percentage of time on open arms; Figure 3a, Table 1) or locomotion on the EPM (number of closed arm entries; Figure 3c), in depressive-like behavior in the FST (percentage immobility; Figure $3 \mathrm{~b}$ ), or in home cage locomotion (distance moved; Figure 3d) compared with unconditioned mice 1 day after SFC.

No effect of SFC on fear of novelty. Mice showed similar pre-conditioning non-social anxiety (Figure 4a, Table 1). One day after SFC, conditioned mice showed similar nonsocial and novel object investigation, but reduced social investigation $(p<0.01$; Figure $4 \mathrm{~b})$ compared with unconditioned mice. 
Table I Overall Effects for the SFC Data

Group effect

Group $\times$ stimulus effect

Short-term social fear (Figure I)

SFC (day I)

Extinction (day 2)

$T(24)=0.89, p=0.38$

Extinction recall (day 3 )

$F(I, 24)=|3.699, p=0.00|^{*}$

$F(8,192)=8.962, p<0.001 *$

$F(1,24)=0.918, p=0.348$

$F(5, I 20)=1.639, p=0.155$

Long-term social fear (Figure 2)

SFC (day I)

Extinction (day 15)

$T(16)=0.08, p=0.94$

Extinction recall (day 16 )

$F(I, I 6)=10.726, p=0.005^{*}$

$F(8,128)=4.406, p<0.001 *$

$F(I, I 6)=4.593, p=0.048$ *

$F(5,80)=1.367, p=0.245$

Specificity of the induced social fear (Figure 3)

General anxiety

Depressive-like behavior

EPM locomotion

Home cage locomotion

Fear of novelty (Figure 4)

SFC (day I)

Extinction (day 2)

Foot-shock exposure (Figure 5)

Short-term social fear by diazepam (Figure 6)

SFC (day I)

Extinction (day 2)

Extinction recall (day 3 )

Long-term social fear by paroxetine (Figure 7)

SFC (day I)

Extinction (day |5)

Extinction recall (day 16)

$$
\begin{aligned}
& T(\mid 4)=0.84, p=0.42 \\
& T(\mid 4)=-0.70, p=0.50 \\
& T(\mid 4)=-0.19, p=0.86 \\
& F(I, \mid 2)<0.00 I, p=0.99
\end{aligned}
$$

$$
\begin{aligned}
& T(\mid 4)=0.43, p=0.67 \\
& F(I, \mid 4)=6.544, p=0.023^{*} \\
& F(I, \mid 4)=1.105, p=0.311
\end{aligned}
$$

$F(8,|| 2)=|| .085, p<0.00 \mid *$

$F(8, I \mid I)=0.327, p=0.954$
$F(24,288)=4.139, p<0.001 *$ $F(15, \mid 80)=1.005, p=0.452$

Abbreviations: EPM, elevated plus maze; SFC, social fear conditioning.

Stimulus effect refers to both non-social and social stimuli during extinction, while during extinction recall it refers to social stimuli only. Student's $t$-tests, one-way or two-way ANOVA for repeated measures followed by Bonferroni's post-hoc test. $* p<0.05$.

No effect of foot-shock exposure on social fear. Exposure to foot shocks in the absence of the social stimulus did not alter social investigation 1 day later (Figure 5, Table 1).

\section{Reversal of Short- and Long-Term Social Fear by Acute Diazepam and Chronic Paroxetine Treatment, Respectively}

Dose-dependent reversal of short-term social fear by diazepam. Acute diazepam dose-dependently reversed social fear in conditioned mice $\left(\mathrm{F}_{(4,44)}=5.164, p=0.022\right.$; Table 2), with doses $>0.5 \mathrm{mg} / \mathrm{kg}$ being unsuccessful in reversing social fear because of their sedative properties (see Table 2 for details). However, these higher doses were not sedative on the EPM and caused a dose-dependent anxiolysis (see Table 2). Mice showed similar pre-conditioning non-social anxiety before treatment (Figure 6a,
Table 1). Conditioned mice received a similar number of foot shocks during SFC (vehicle $2.3 \pm 0.15$ vs $0.5 \mathrm{mg} / \mathrm{kg}$ diazepam $2.2 \pm 0.19 ; \mathrm{T}_{(18)}=0.42$, n.s.). One day later, the four groups showed similar non-social investigation. Although in conditioned diazepam-treated mice social investigation returned to levels found in unconditioned mice, conditioned vehicle-treated mice showed reduced social investigation compared with all other groups $(p<0.05$, Figure 6b). No difference between the mice was found during extinction recall (Figure 6c).

Reversal of long-term social fear by paroxetine. Mice showed similar pre-conditioning non-social anxiety before treatment (Figure 7a, Table 1). Conditioned mice received a similar number of foot shocks during SFC (vehicle $2.38 \pm 0.18 v s$ paroxetine $2.31 \pm 0.16 ; T_{(14)}=0.26$, n.s.). After 15 days, the four groups showed similar non-social investigation. Although in conditioned paroxetine-treated mice 

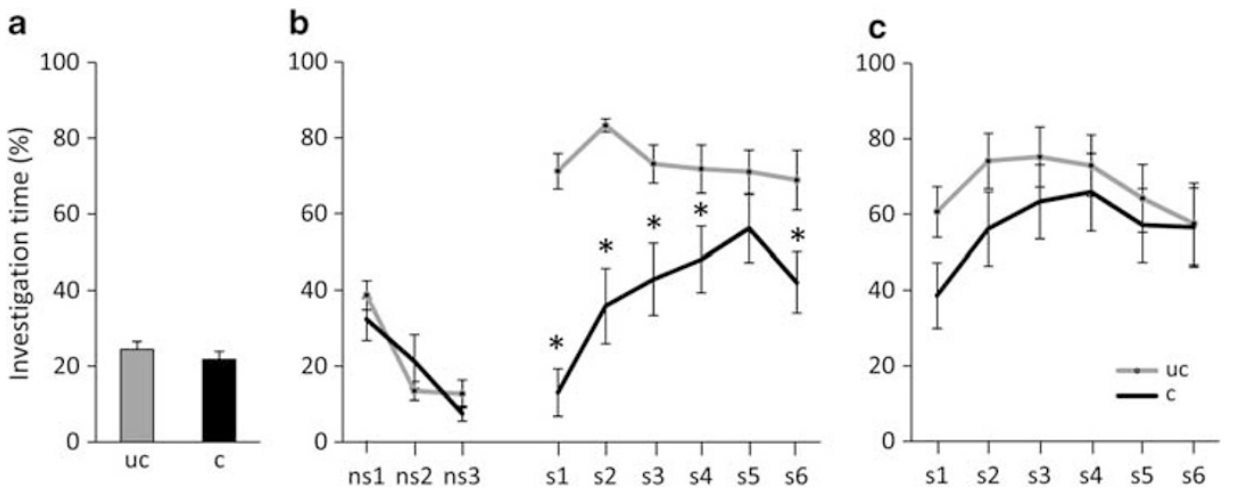

Figure I Social fear conditioning (SFC) induces short-term social fear in mice. (a) Pre-conditioning investigation of the non-social stimulus (empty cage) by unconditioned (uc) and conditioned (c) mice during SFC (day I; $n=13$ per group). (b) Investigation of non-social (ns I-ns3) and social (cages with mice; sl-s6) stimuli during extinction on day 2 (3-min exposure to stimulus, 3-min inter-exposure interval). (c) Investigation of social stimuli (sI-s6) during extinction recall on day 3. Data represent mean percentage of investigation time \pm SEM. $* p<0.05$ vs uc mice.
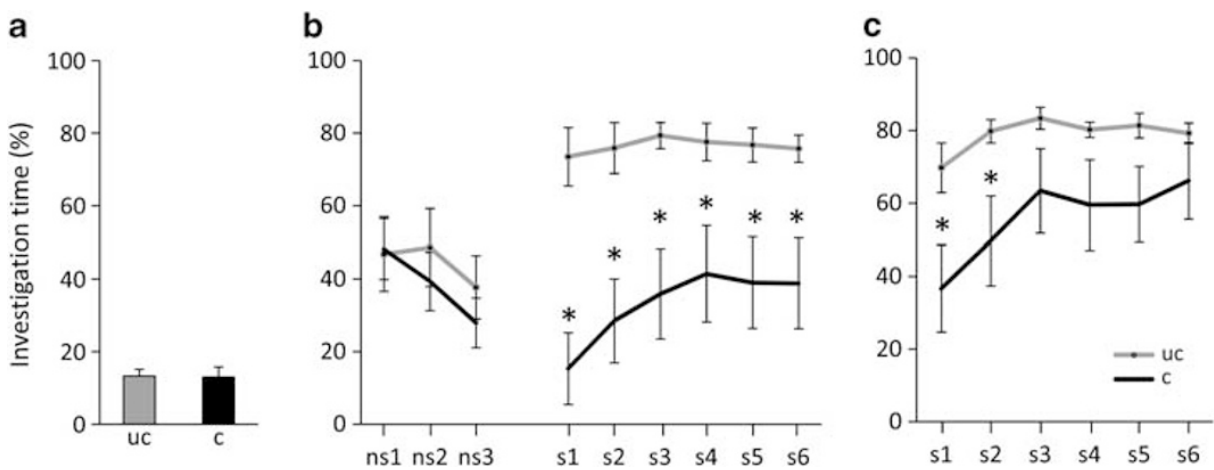

Figure 2 Social fear conditioning (SFC) induces long-term social fear in mice. (a) Pre-conditioning investigation of the non-social stimulus (empty cage) by unconditioned (uc) and conditioned (c) mice during SFC (day I; $n=9$ per group). (b) Investigation of non-social (ns I-ns3) and social (cages with mice; sI-s6) stimuli during extinction on day 15 (3-min exposure to stimulus, 3-min inter-exposure interval). (c) Investigation of social stimuli (sI-s6) during extinction recall on day 16. Data represent mean percentage of investigation time \pm SEM. $* p<0.05$ vs uc mice.
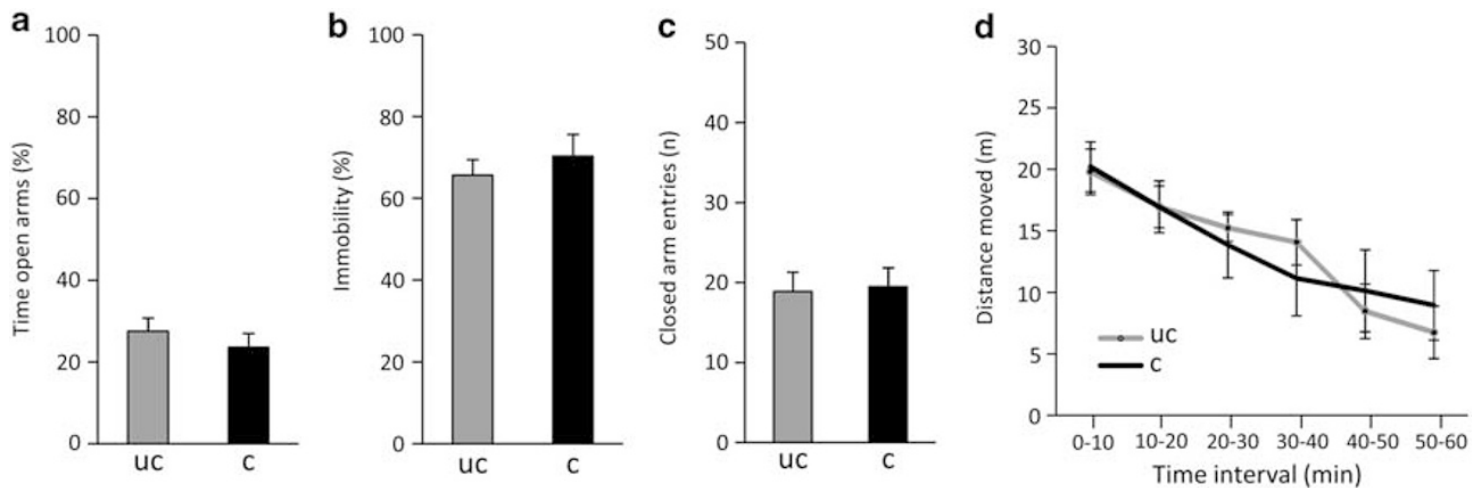

Figure 3 No effect of social fear conditioning (SFC) on general anxiety on the elevated plus maze (EPM) (a), depressive-like behavior in the forced swim test (b), and locomotor activity on the EPM (c) and in the home cage (d). Data represent means \pm SEM for $n=7$ to 8 mice (separate groups). c, conditioned; uc, unconditioned.

social investigation returned to levels found in unconditioned mice, conditioned vehicle-treated mice showed reduced social investigation compared with all other groups $(p<0.05$, Figure $7 \mathrm{~b})$. During extinction recall, conditioned vehicle-treated mice still showed reduced social investigation compared with all other groups $(p<0.05$, Figure $7 c)$.

\section{DISCUSSION}

To the best of our knowledge, this study describes the first animal model of SAD that specifically induces social anxiety without potentially confounding alterations in other behavioral measures. We show that the novel SFC model induces 

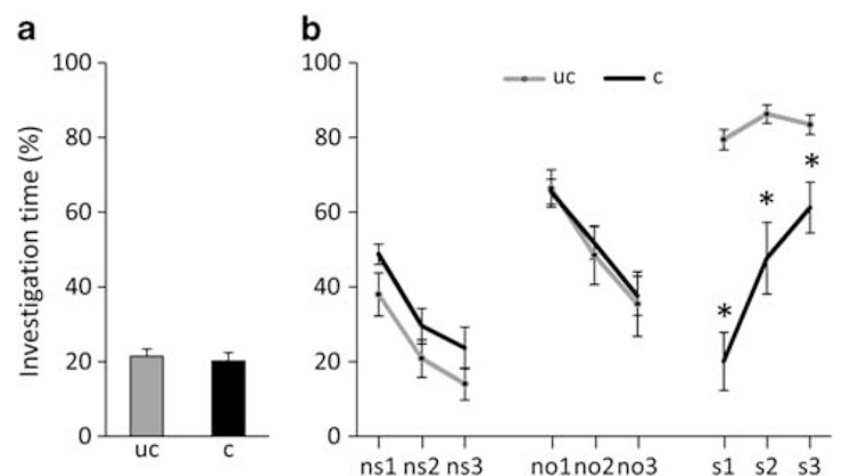

Figure 4 Social fear conditioning (SFC) does not induce fear of novelty. (a) Pre-conditioning investigation of the non-social stimulus (empty cage) by unconditioned (uc) and conditioned (c) mice during SFC (day I; $n=8$ per group). (b) Investigation of non-social stimuli (ns I-ns3), novel object stimuli (cages with objects; nol-no3), and social stimuli (cages with mice; sl-s6) during novel object investigation on day 2 (3-min exposure to stimulus, 3-min inter-exposure interval). Data represent mean percentage of investigation time \pm SEM. $* p<0.05$ vs uc mice.

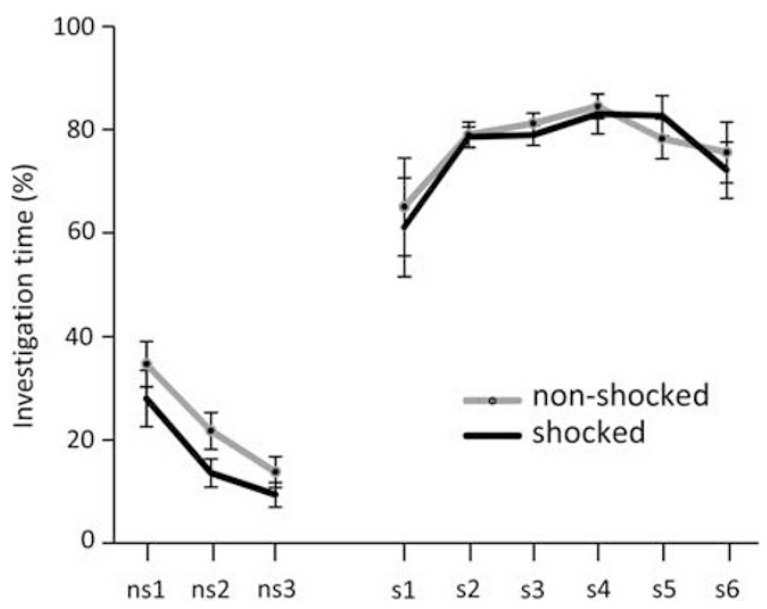

Figure 5 Exposure to five electric foot shocks in the absence of a social stimulus does not induce social fear. Investigation of non-social (empty cages; nsI-ns3) and social (cages with mice; sI-s6) stimuli by non-shocked and shocked mice ( $n=8$ per group) during extinction I day after foot-shock exposure (3-min exposure to stimulus, 3-min inter-exposure interval). Data represent mean percentage of investigation time \pm SEM.

both short- and long-term specific fear of social stimuli, and that this fear sensitizes over time. Furthermore, SFC does not induce other behavioral changes that might account for the observed social fear, such as fear of novelty, increased general anxiety, depressive-like behavior, and impaired locomotion. We further show that social fear is dosedependently reversed by acute diazepam; at a dose that is not anxiolytic in a non-social context. Finally, we show that chronic paroxetine treatment reverses social fear, similar to the best outcomes in SAD patients, validating the SFC model. Therefore, the SFC model represents a unique and novel model to gain a better understanding of the underlying etiology of SAD and to test compounds with novel mechanisms of action that could provide better treatment outcome for patients.

Despite its prevalence and symptom severity, the etiology of SAD remains poorly understood, due in part to a lack of appropriate animal models. Currently, lasting social anxiety/avoidance in both rats and mice is induced by two main traumatic stress procedures, namely social defeat and footshock exposure. Social defeat is used both acutely- one defeat by a dominant male and chronically- repeated defeat by several dominant males (for reviews see Huhman, 2006; Yan et al, 2010). Foot-shock exposure is used as exposure to a single (Short and Maier, 1993; Siegmund and Wotjak, 2007) or to repeated foot shocks (Haller and Bakos, 2002; Louvart et al, 2005; Mikics et al, 2008a). Although social defeat and foot-shock exposure decrease social investigation, they also lead to behavioral alterations including increased general anxiety, depression, and impaired locomotion that might account for the observed social deficit (Denmark et al, 2010; Hollis et al, 2010). Furthermore, in the case of acute social defeat, the induced social avoidance is generally directed toward the con-specific that performed the defeat (Lai et al, 2005; Lukas et al, 2011). Although such models are useful and have improved our understanding of SAD, there is a need for animal models that lead to specific social fear, without any confounding behavioral alterations, to further elucidate the mechanisms underlying SAD.

Our SFC model is based on operant conditioning, where animals learn to associate a voluntary behavior with its consequences. When the consequence is favorable the behavior will occur more frequently, whereas when the consequence is unfavorable the behavior will occur less frequently (Thorndike, 1933; White, 1989). SFC implies punishing naïve mice when investigating a con-specific and results in fear and avoidance of social stimuli. The social fearful phenotype is expressed in reduced investigation of social stimuli and intense aversive responses toward them, such as freezing (absence of movement except that required for respiration, Fanselow, 1980), stretched approaches, and defensive burying (Table 3). Although all these behaviors have been linked with increased anxiety and fear, the reduced social investigation was the most robust indicator of social fear in our paradigm and, therefore, the one we focused on. Furthermore, as none of the unconditioned mice showed freezing, stretched approaches, or defensive burying, by using social investigation as the main readout of social fear direct comparison with unconditioned mice is possible.

To evaluate the effects of SFC on social fear, we used a modified version of the social approach/avoidance paradigm (Berton et al, 2006), where we first exposed mice to non-social stimuli, ie, empty cages to exclude possible confounding effects due to fear of the cage itself. As the stimulus mouse used during SFC was enclosed in a cage that was identical to the cages used as non-social stimuli during extinction, the cage additionally served as a cue and, therefore, elicited a fear response in conditioned mice (Table 4). However, this fear was extinguished by placing the empty cage in the home cage of the mice over night. As non-social investigation was not decreased in conditioned mice after extinguishing the fear of the cage, it is unlikely that fear renewal to the cage occurred and thereby decreased social investigation (Table 4). Furthermore, exposure to non-social stimuli during extinction did not affect the level of social investigation in either conditioned 
Table 2 Dose-Dependent Effects of Diazepam in the Social Fear Conditioning Paradigm and the Elevated Plus Maze (EPM)

\begin{tabular}{|c|c|c|c|c|c|c|}
\hline Conditioning & Treatment & $\%$ NSI & $\% \mathbf{S I}$ & $\%$ Sedative index & CA entries & Time OA \\
\hline \multirow[t]{5}{*}{ Unconditioned mice } & Vehicle & $23.6 \pm 1.7$ & $69.6 \pm 2.5$ & $0 \pm 0$ & $100 \pm 5.6$ & $100 \pm 11.0$ \\
\hline & $0.5 \mathrm{Dia}$ & $20.3 \pm 3.0$ & $68.8 \pm 2.4$ & NA & $88.5 \pm 10.9$ & $97.8 \pm 6.0$ \\
\hline & $0.75 \mathrm{Dia}$ & $7.6 \pm 1.8 *$ & $40.1 \pm 3.2 *$ & $28.4 \pm 4.8^{*}$ & $99.5 \pm 7.7$ & $120.2 \pm 9.0$ \\
\hline & 1.0 Dia & $12.2 \pm 5.3^{*}$ & $31.8 \pm 12.2 *$ & $34.3 \pm 13.9 *$ & $75.1 \pm 11.5$ & $|5| . \mid \pm 66.0$ \\
\hline & 1.25 Dia & $4.7 \pm 3.7 *$ & $7.9 \pm 2.3 *$ & $51.8 \pm 8.0 *$ & $115.6 \pm 13.8$ & $238.7 \pm 34.3 *$ \\
\hline & $0.5 \mathrm{Dia}$ & $22.1 \pm 6.3$ & $64.6 \pm 7.7 *$ & NA & - & - \\
\hline & 0.75 Dia & $18.3 \pm 4.6$ & $27.0 \pm 12.2$ & NA & - & - \\
\hline & 1.0 Dia & $8.4 \pm 2.3$ & $19.8 \pm 8.8$ & NA & - & - \\
\hline & I.25 Dia & $13.9 \pm 7.1$ & $10.1 \pm 5.8$ & NA & - & - \\
\hline
\end{tabular}

Abbreviations: CA, closed arms of the EPM; NA, not analyzed; NSI, non-social investigation; OA, open arms of the EPM; SFC, social fear conditioning; SI, social investigation.

Unconditioned and conditioned mice were injected intraperitoneally either with vehicle (5 ml/ $/ \mathrm{kg}$ saline) or with diazepam (Dia; $0.5,0.75,1.0$, or $1.25 \mathrm{mg} / \mathrm{kg}$ ) $30 \mathrm{~min}$ before extinction in the SFC paradigm or EPM testing. Data represent mean values \pm SEM. The sedative index is defined as the percentage of time lacking muscle tone and movement. $* p<0.05$.
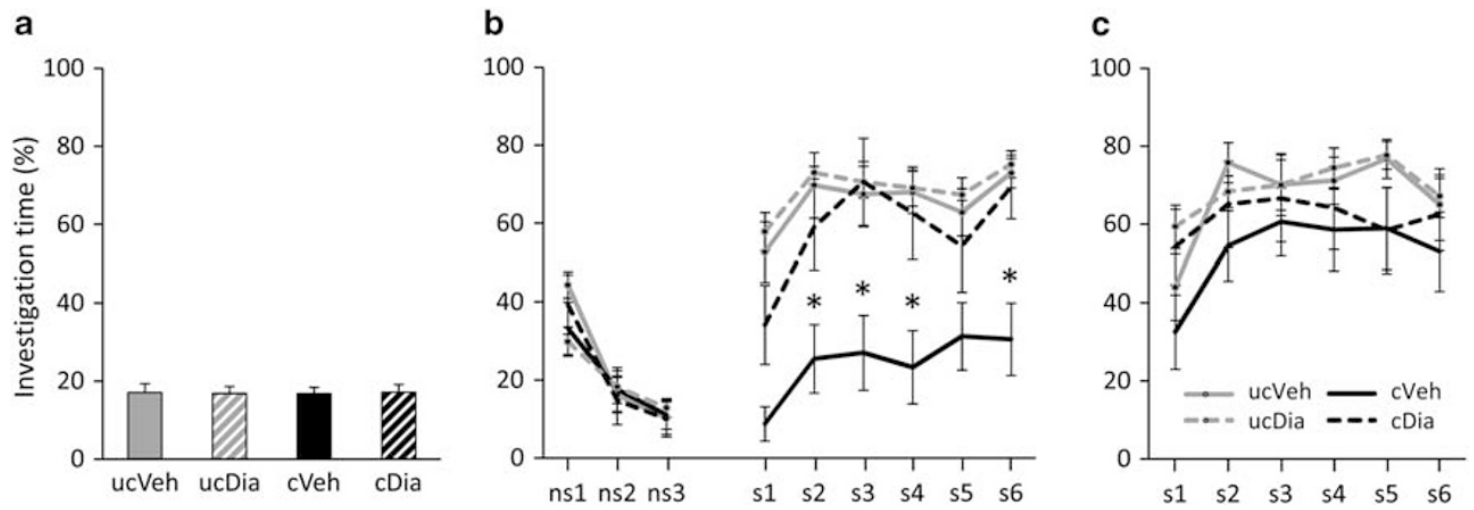

Figure 6 Acute diazepam treatment reverses short-term social fear. (a) Pre-conditioning investigation of the non-social stimulus (empty cage) during social fear conditioning (day I; $n=10$ per group). (b) Investigation of non-social (ns I-ns3) and social (cages with mice; sl-s6) stimuli during extinction on day 2 (3-min exposure to stimulus, 3-min inter-exposure interval). Unconditioned (uc) and conditioned (c) mice were injected intraperitoneally either with vehicle (Veh; $5 \mathrm{ml} / \mathrm{kg}$ saline) or with diazepam (Dia; $0.5 \mathrm{mg} / \mathrm{kg}$ ) $30 \mathrm{~min}$ before extinction. (c) Investigation of social stimuli (sI-s6) during extinction recall on day 3. Data represent mean percentage of investigation time \pm SEM. $* p<0.05$ vs the other three groups.
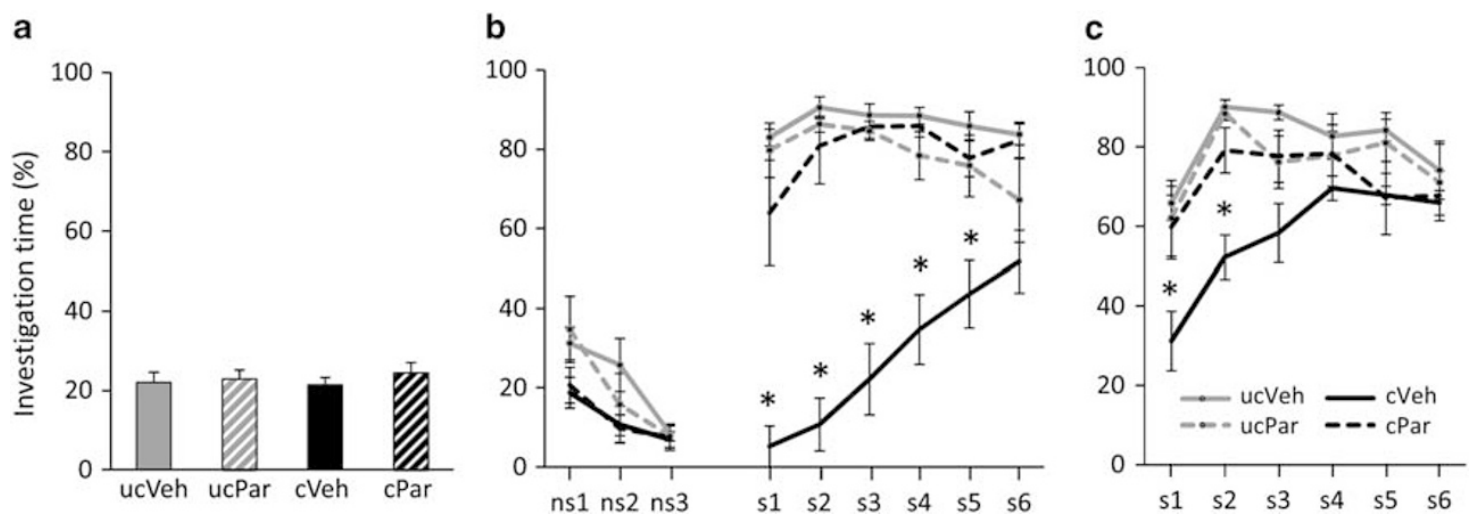

Figure 7 Chronic paroxetine treatment reverses long-term social fear. (a) Pre-conditioning investigation of the non-social stimulus (empty cage) during social fear conditioning (SFC; day I; $n=8$ per group). Paroxetine (Par) was administered over I 4 days in the drinking water (Veh) of unconditioned (uc) and conditioned (c) mice starting I day after SFC. (b) Investigation of non-social (ns I-ns3) and social (cages with mice; s I-s6) stimuli during extinction on day I5 (3-min exposure to stimulus, 3-min inter-exposure interval). (c) Investigation of social stimuli (sI-s6) during extinction recall on day I6. Data represent mean percentage of investigation time \pm SEM. $* p<0.05$ vs the other three groups. 
Table 3 Behavioral Changes Indicating Social Fear After Social Fear Conditioning

\begin{tabular}{|c|c|c|c|c|}
\hline & Decreased SI & Freezing & Stretched approaches & Defensive burying \\
\hline Short-term social fear (Figure I) & $92.3 \%(12 / 13)$ & $61.5 \%(8 / 13)$ & $61.5 \%(8 / 13)$ & $38.5 \%(5 / 13)$ \\
\hline Long-term social fear (Figure 2) & $100 \%(8 / 9)$ & $88.9(8 / 9)$ & $55.6 \%(5 / 9)$ & $22.2(2 / 9)$ \\
\hline Fear of novelty (Figure 4) & $100 \%(8 / 8)$ & $75 \%(6 / 8)$ & $50 \%(4 / 8)$ & $0 \%(0 / 8)$ \\
\hline Foot-shock exposure (Figure 5) & $0 \%(0 / 8)$ & $0 \%(0 / 8)$ & $12.55(1 / 8)$ & $0 \%(0 / 8)$ \\
\hline Short-term social fear by diazepam (Figure 6) & $90 \%(9 / 10)$ & $90 \%(9 / 10)$ & $80 \%(8 / 10)$ & $30 \%(3 / 10)$ \\
\hline
\end{tabular}

Decreased social investigation (SI) represents the percentage of conditioned mice in each experiment that showed a decrease of at least $50 \%$ in investigation of the first social stimulus compared with the mean of their respective unconditioned mice during extinction. Freezing, stretched approaches, and defensive burying represent the percentage of conditioned mice that showed those behaviors when the social stimuli were in their home cage during extinction. None of the unconditioned mice showed these behaviors. Data from Figures 6 and 7 include only conditioned vehicle-treated mice.

Table 4 Investigation of the Non-Social (nsI-ns3) and Social Stimuli (sl-s6) During Extinction in Relation to Over Night Exposure to the Empty Cage and Exposure to Non-Social Stimuli During Extinction

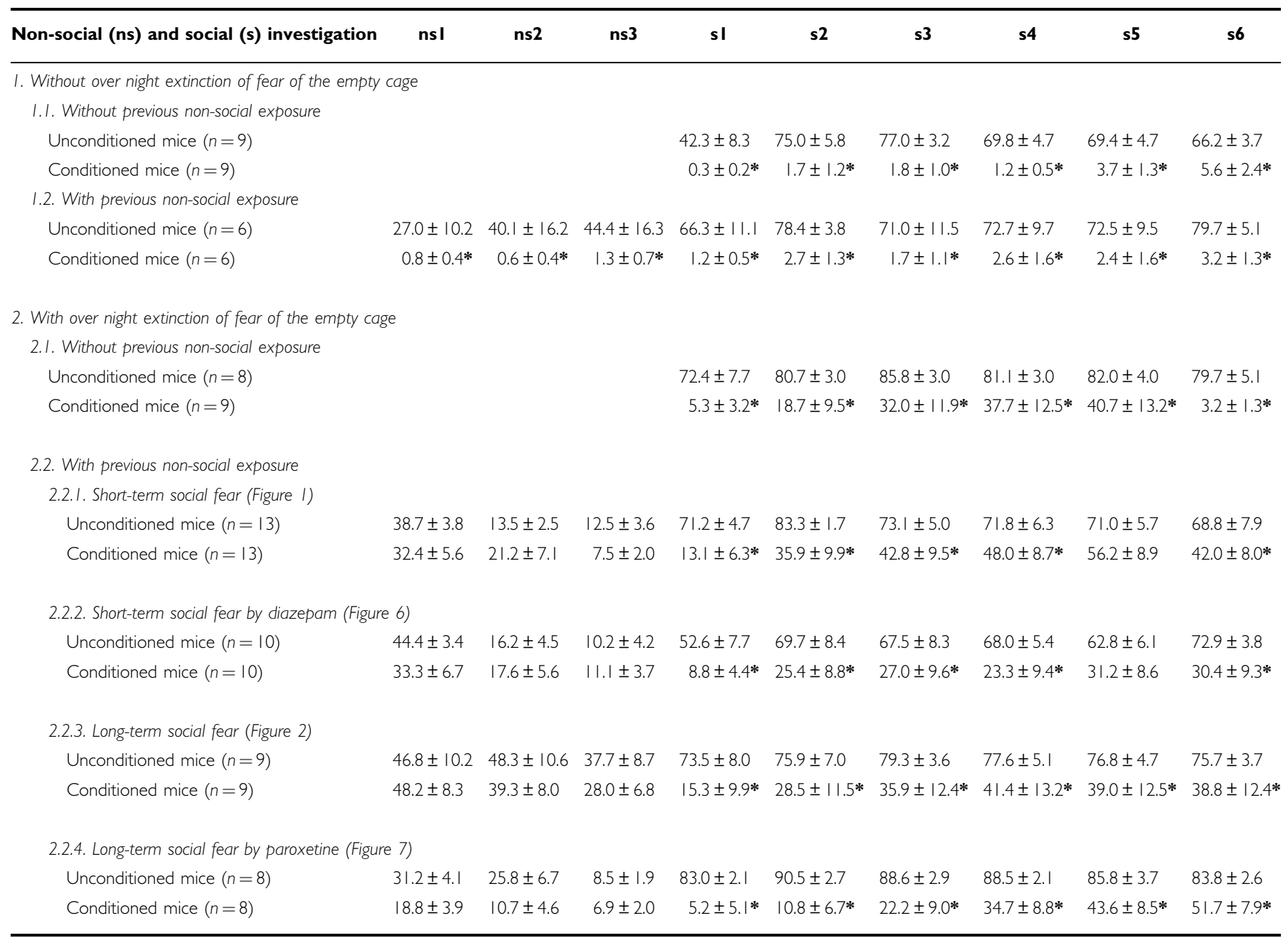

Mice were social fear conditioned and the empty cage was either placed or not in their home cage over night. Extinction was assessed I day or 15 days later. Data represent mean percentage of investigation time \pm SEM.

*p $<0.05$ vs unconditioned mice. Statistical significance shown in points 2.2.2. and 2.2.4. Represents those from all treatment groups, as shown in the results section.

or unconditioned mice (Table 4). Therefore, to allow for a within-individual assessment of non-social and social fear, mice were exposed to both non-social and social stimuli throughout the experiments. For assessing social investigation, mice were repeatedly exposed to different unfamiliar con-specifics. Different individuals were used for two 
reasons. First, we aimed to obtain a reversal of social fear in general and not a reversal of fear toward a specific individual. Second, we aimed to maintain high interest in the social stimuli as repeated exposure to the same conspecific has been shown to decrease social interest in both mice (Ferguson et al, 2002; Choleris et al, 2009) and rats (Thor et al, 1982; Popik and van Ree, 1998). This exposurelike paradigm is similar to exposure therapy during CBT in humans, where patients are repeatedly exposed to the feared situation.

SFC induced both short- and long-term specific fear of social stimuli. Social investigation increased with each exposure to the social stimuli, indicating gradual social fear extinction, which is similar to the outcome during CBT in SAD patients (Clark et al, 2003), and extinction after cued and context fear conditioning in mice and rats (Myers and Davis, 2002). When the extinction procedure was performed 1 day after SFC, social fear was completely reversed by the next day, during extinction recall. However, when the extinction was performed 15 days after SFC, conditioned mice still showed social fear during extinction recall, indicating that the social fear sensitized over time. Previous studies also showed sensitization of fear responses over time after single or repeated foot-shock exposure (Siegmund and Wotjak, 2007; Mikics et al, 2008a), suggesting that the circuitry underlying the conditioned social fear not only remains stable, but may even strengthen over time. Moreover, the maintenance of social fear over both the short- and long-term not only offers the possibility to test medication with fast onset of action, such as benzodiazepines, but also with a delayed onset of action, such as antidepressants (Katz et al, 2006; Mitchell, 2006; Priest, 2006).

Unlike acute social defeat, SFC induced a general fear of social stimuli, which was not limited to the stimulus to which the mouse has been conditioned, but extended to unfamiliar social stimuli as well. This general social fear is similar to the general social avoidance induced by chronic social defeat (Avgustinovich et al, 2005; Berton et al, 2006), where several dominant males are consecutively used to defeat a subordinate animal (Miczek, 1979; Rodgers and Randall 1986; Kabbaj et al, 2001). However, chronic social defeat also increased general anxiety (Keeney and Hogg, 1999; Avgustinovich et al, 2005; Berton et al, 2006; Denmark et al, 2010), decreased locomotor activity (Koolhaas et al, 1997; Rygula et al, 2005), and induced a depressive-like phenotype (Avgustinovich et al, 2005; Rygula et al, 2005; Berton et al, 2006; Hollis et al, 2010). Correspondingly, these behavioral changes might account for the decreased social investigation observed. Unlike chronic social defeat, SFC induced a specific fear of social stimuli without inducing changes in general anxiety on the EPM, depressive-like behavior in the FST, or in home cage and novel environment (EPM) locomotion. We could also show that the induced social fear was specific to a social stimulus, as novel objects that were similar in size and color to the social stimuli did not induce fear responses in conditioned mice. Thus, in future studies it would be interesting to compare treatments that are effective in the SFC paradigm in such social defeat models to determine their specificity.

The SFC model involves the use of aversive stimuli, in this case electric foot shocks. Previous studies have shown that foot-shock exposure alone decreased social investigation for both short- and long-term, however, only when assessed in a novel environment (Short and Maier, 1993; Haller and Bakos, 2002; Haller et al, 2003; Louvart et al, 2005; Leveleki et al, 2006; Siegmund and Wotjak, 2007; Mikics et al, $2008 \mathrm{a}, \mathrm{b})$. When social investigation was assessed in the home cage, no differences were found, suggesting that the former result is due to novelty-induced anxiety (Mikics et al, 2008a). Shock exposure also increased general anxiety and decreased locomotion and exploratory behavior in the open field and EPM (Van Dijken et al, 1992; Bruijnzeel et al, 2001; Pijlman and van Ree, 2002; Kavushansky et al, 2009), indicating that the decreased social investigation observed after foot-shock exposure may rather be due to an increase in general anxiety. Our paradigm assessed the experimental mice in their home cage, which reduces the possibility of novelty-induced anxiety. Moreover, we did not observe changes in home cage social investigation when mice were exposed to foot shocks in the absence of the stimulus mouse, indicating that the fear induced during SFC is a result of the association between the experienced pain and investigation of a con-specific rather than a direct result of foot-shock exposure.

Having shown the specificity of the fear induced during SFC, we assessed the therapeutic efficacy of benzodiazepines (diazepam) and antidepressants (paroxetine) in reversing social fear in our model. Although $\beta$-blockers can be beneficial in humans, their efficacy is limited to performance anxiety (Faigel, 1991; Liebowitz et al, 1992), therefore we did not assess them in the SFC paradigm.

Acute diazepam treatment dose-dependently reversed short-term social fear, without further increasing social investigation in unconditioned mice. Doses $>0.5 \mathrm{mg} / \mathrm{kg}$ $(0.75,1.0$, and $1.25 \mathrm{mg} / \mathrm{kg})$ had sedative effects in the home cage and even reduced investigation in unconditioned mice, counter indicating, therefore, their use in the SFC paradigm (Table 2). Diazepam reversed social fear at a dose $(0.5 \mathrm{mg} / \mathrm{kg})$ that did not alter general anxiety on the EPM (Table 2). We could only demonstrate anxiolytic effects of diazepam on the EPM at a dose of $1.25 \mathrm{mg} / \mathrm{kg}$, confirming recent findings (Hascoët et al, 2000a). The sedative effect of doses $>0.5 \mathrm{mg} / \mathrm{kg}$ diazepam might not have been observed in previous studies, as the increased arousal level in novel environments, such as the EPM, open field, and light-dark box, may have masked the sedative effect of diazepam.

Chronic paroxetine treatment, started 1 day after SFC to prevent possible confounding effects on fear memory consolidation, was also successful in reversing long-term social fear, without further increasing social investigation in unconditioned mice. However, acute SSRI treatment increased social fear in conditioned mice (data not shown). This is in line with data showing that SSRI treatment reduces cued fear after chronic treatment, but increases cued fear after acute treatment (Burghardt et al, 2004, 2007). All in all, the reversal of social fear by medication used for SAD patients provides predictive validity to the SFC model.

Finally, it is of interest to note that the use of the SFC model is not restricted to male CD1 mice, as shown in this study. Preliminary data have shown that the paradigm can also be used successfully in inbred lines such as C57/B16, and in a different species, namely Wistar rats (data not shown). This further demonstrates the utility of the novel paradigm for gaining a better understanding of the etiology 
of SAD. Moreover, SFC has not been used to induce social fear in female mice or rats yet, which, however, would be promising given the higher prevalence of SAD in women (Schneier et al, 1992; Talepasand and Nokani 2010).

In summary, we have established a novel SFC paradigm that induces specific and long-lasting fear of social stimuli in naïve mice, and shows both face and predictive validity to $\mathrm{SAD}$. The induced social fear is specific to several social stimuli and not the result of fear of novelty, increased general anxiety, depressive-like behavior, or impaired locomotion. Our model might, therefore, be used to gain a better understanding of the underlying causes and mechanisms of SAD in humans and also to test compounds with novel mechanisms of action that could provide better treatment outcome for these patients.

\section{ACKNOWLEDGEMENTS}

We thank Dr Michael Lukas for critically reading the manuscript. IT received financial support from the Bayerische Forschungsstiftung. IDN received financial support from the BMBF and Deutsche Forschungsgemeinschaft.

\section{DISCLOSURE}

The authors declare no conflict of interest.

\section{REFERENCES}

American Psychiatric Association (1994). Diagnostic and Statistical Manual of Mental Disorders 4th edn American Psychiatric Association Press: Washington, DC.

Avgustinovich DF, Kovalenko IL, Kudryavtseva NN (2005). A model of anxious depression: persistence of behavioral pathology. Neurosci Behav Physiol 35: 917-924.

Baldwin D, Bobes J, Stein DJ, Scharwaechter I, Faure M (1999). Paroxetine in social phobia/social anxiety disorder: randomized, double blind, placebo-controlled study. $B r J$ Psychiatry 175: 120-126.

Berton O, McClung CA, Dileone RJ, Krishnan V, Renthal W, Russo SJ (2006). Essential role of BDNF in the mesolimbic dopamine pathway in social defeat stress. Science 311: 864-868.

Bögels SM, Alden L, Beidel DC, Clark LA, Pine DS, Stein MB et al. (2010). Social anxiety disorder: questions and answers for the DSM-V. Depress Anxiety 27: 168-189.

Bruijnzeel AW, Stam R, Croiset G, Wiegant VM (2001). Long-term sensitization of cardiovascular stress responses after a single stressful experience. Physiol Behav 73: 81-86.

Burghardt NS, Bush DEA, McEven BS, LeDoux JE (2007). Acute selective serotonin reuptake inhibitors increase conditioned fear expression: blockade with a 5-HT2c receptor antagonist. Biol Psychiatry 62: 1111-1118.

Burghardt NS, Sullivan GM, McEven BS, Gorman JM, LeDoux JE (2004). The selective serotonin reuptake inhibitor citalopram increases fear after acute treatment but reduces fear with chronic treatment: a comparison with tianeptine. Biol Psychiatry 55: 1171-1178.

Cherng CG, Lin PS, Chuang JY, Chang WT, Lee YS, Kao GS et al. (2010). Presence of conspecifics and their odor-impregnated objects reverse stress-decreased neurogenesis in mouse dentate gyrus. J Neurochem 112: 1138-1146.

Choleris E, Clipperton-Allen AE, Phan A, Kavaliers M (2009). Neuroendocrinology of social information processing in rats and mice. Front Neuroendocrinol 30: 442-459.
Clark DM, Ehlers A, McManus F, Hackmann A, Fennell M, Campbell $\mathrm{H}$ et al. (2003). Cognitive therapy vs fluoxetine in generalised social phobia: a randomised placebo-controlled trial. J Consult Clin Psychol 71: 1058-1067.

Corbett R, Hartman H, Kerman LL, Woods AT, Strupczewski JT, Helsley GC et al. (1993). Effects of atypical antipsychotic agents on social behavior in rodents. Pharmacol Biochem Behav 45: 9-17.

Dalvi A, Rodgers RJ (1996). GABAergic influences on plus-maze behaviour in mice. Psychopharmacology 128: 380-397.

Da-Rocha Jr MA, Puech AJ, Thiébot MH (1997). Influence of anxiolytic drugs on the effects of specific serotonin reuptake inhibitors in the forced swimming test in mice. J Psychopharmacol 11: 211-218.

den Boer JA (1997). Social phobia: epidemiology, recognition, and treatment. BMJ 315: 796-800.

Denmark A, Tien D, Wong K, Chung A, Cachat J, Goodspeed J et al (2010). The effects of chronic social defeat stress on mouse selfgrooming behavior and its patterning. Behav Brain Res 208: 553-559.

Elizalde N, Gil-Bea FJ, Ramírez MJ, Aisa B, Lasheras B, Del Rio J et al (2008). Long-lasting behavioral effects and recognition memory deficit induced by chronic mild stress in mice: effect of antidepressant treatment. Psychopharmacology 199: 1-14.

Faigel HC (1991). The effect of beta blockade on stress-induced cognitive dysfunction in adolescents. Clin Pediatr 30: 441-445.

Fanselow MS (1980). Conditioned and unconditioned components of post-shock freezing. J Biol Sci 15: 177-182.

Fedoroff IC, Taylor S (2001). Psychological and pharmacological treatments of social phobia: a meta-analysis. J Clin Psychopharmacol 21: 311-324.

Ferguson JN, Young LJ, Insel TR (2002). The neuroendocrine basis of social recognition. Front Neuroendocrinol 23: 200-224.

Gould S, Buckminster MH, Pollack MW, Yap L (1997). Cognitivebehavioral and pharmacological treatment for social phobia: a meta-analysis. Clin Psychol Sci Pract 4: 291-306.

Haller J, Bakos N (2002). Stress-induced social avoidance: a new model of stress induced anxiety? Physiol Behavior 77: 327-332.

Haller J, Leveleki C, Baranyi J, Mikics E, Bakos N (2003). Stress, social avoidance and anxiolytics: a potential model of stressinduced anxiety. Behav Pharmacol 14: 439-446.

Hascoët M, Bourin M, Colombel MC, Fiocco AJ, Baker GB (2000a). Anxiolytic-like effects of antidepressants after acute administration in a four-plate test in mice. Pharmacol Biochem Behav 65: 339-344.

Hascoët M, Bourin M, Dhonnchadha BA (2000b). The influence of buspirone, and its metabolite 1-PP, on the activity of paroxetine in the mouse light/dark paradigm and four plates test. Pharmacol Biochem Behav 67: 45-53.

Hollis F, Wang H, Dietz D, Gunjan A, Kabbaj M (2010). The effects of repeated social defeat on long-term depressive-like behavior and short-term histone modifications in the hippocampus in male Sprague-Dawley rats. Psychopharmacology 211: 69-77.

Huhman KL (2006). Social conflict models: can they inform us about human psychopathology? Horm Behav 50: 640-646.

Kabbaj M, Norton CS, Kollack-Walker S, Watson SJ, Robinson TE, Akil H (2001). Social defeat alters the acquisition of cocaine selfadministration in rats: role of individual differences in cocainetaking behavior. Psychopharmacology 158: 382-387.

Katz MM, Frazer A, Bowden CL (2006). 'Delay' hypothesis of onset of antidepressant action. Br J Psychiatry 188: 586.

Kavushansky A, Ben-Shachar D, Richter-Levin G, Klein E (2009). Physical stress differs from psychosocial stress in the pattern and time-course of behavioral responses, serum corticosterone and expression of plasticity-related genes in the rat. Stress 12: 412-425.

Keeney AJ, Hogg S (1999). Behavioural consequences of repeated social defeat in the mouse: preliminary evaluation of a potential animal model of depression. Behav Pharmacol 10: 753-764.

Kessler RC, Berglund P, Demler O, Jin R, Merikangas KR, Walters EE (2005a). Lifetime prevalence and age-of-onset 
distributions of DSM-IV disorders in the National Comorbidity Survey Replication. Arch Gen Psychiatry 62: 593-602.

Kessler RC, Chiu WT, Demler O, Merikangas KR, Walters EE (2005b). Prevalence, severity, and comorbidity of 12-month DSM-IV disorders in the National Comorbidity Survey Replication. Arch Gen Psychiatry 62: 617-627.

Kessler RC, Stein MB, Berglund P (1998). Social phobia subtypes in the National Comorbidity Survey. Am J Psychiatry 155: 613-619.

Koolhaas JM, Meerlo P, de Boer SF, Strubbe JH, Bohus B (1997). The temporal dynamics of the stress response. Neurosci Biobehav Rev 21: 775-782.

Lai WS, Ramiro LL, Yu HA, Johnston RE (2005). Recognition of familiar individuals in golden hamsters: a new method and functional neuroanatomy. J Neurosci 25: 11239-11247.

Leveleki C, Sziray N, Levay G, Barsvári B, Soproni K, Mikics E et al. (2006). Pharmacological evaluation of the stress-induced social avoidance model of anxiety. Brain Res Bull 69: 153-160.

Liebowitz MR, Schneier FR, Campeas R, Hollander E, Hatterer J, Fyer A (1992). Phenelzine vs atenolol in social phobia: a placebocontrolled comparison. Arch Gen Psychiatry 49: 290-300.

Lister RG (1987). The use of a plus-maze to measure anxiety in the mouse. Psychopharmacol 92: 180-185.

Louvart H, Maccari S, Ducrocq F, Thomas P, Darnaudery M (2005). Long-term behavioural alterations in female rats after a single intense footshock followed by situational reminders. Psychoneuroendocrinology 30: 316-324.

Lukas M, Toth I, Reber SO, Slattery DA, Veenema AH, Neumann ID (2011). The neuropeptide oxytocin facilitates pro-social behavior and prevents social avoidance in rats and mice. Neuropsychopharmacology 36: 2159-2168.

Massé F, Hascoët M, Bourin M (2005). Alpha2-Adrenergic agonists antagonise the anxiolytic-like effect of antidepressants in the four-plate test in mice. Behav Brain Res 164: 17-28.

Miczek KA (1979). A new test for aggression in rates without aversive stimulation: differential effects of $\mathrm{D}$-amphetamine and cocaine. Psychopharmacology 60: 253-259.

Mikics E, Baranyi J, Haller J (2008b). Rats exposed to traumatic stress bury unfamiliar objects - a novel measure of hypervigilance in PTSD models? Physiol Behav 94: 341-348.

Mikics E, Tóth M, Varjú P, Gereben B, Liposits Z, Ashaber M et al (2008a). Lasting changes in social behavior and amygdala function following traumatic experience induced by a single series of foot-shocks. Psychoneuroendocrinology 33: 1198-1210.

Mitchell AJ (2006). Two-week delay in onset of action of antidepressants: new evidence. Br J Psychiatry 188: 105-106.

Myers KM, Davis M (2002). Behavioral and neural analysis of extinction. Neuron 36: 567-584.

Niesink RJ, Van Ree JM (1982). Short-term isolation increases social interactions of male rats: a parametric analysis. Physiol Behav 29: 819-825.

Pellow S, Chopin P, File SE, Briley M (1985). Validation of open:closed arm entries in an elevated plus-maze as a measure of anxiety in the rat. J Neurosci Methods 14: 149-167.

Pijlman FT, van Ree JM (2002). Physical but not emotional stress induces a delay in behavioural coping responses in rats. Behav Brain Res 136: 365-373.

Popik P, van Ree JM (1998). Neurohypophyseal peptides and social recognition in rats. Prog Brain Res 119: 415-436.

Porsolt RD, Bertin A, Jalfre M (1977). Behavioral despair in mice: a primary screening test for antidepressants. Arch Int Pharmacodyn Ther 29: 327-336.

Priest RG (2006). Delay in onset of action of antidepressants. Br J Psychiatry 189: 469-470.

Reber SO, Birkeneder L, Veenema AH, Obermeier F, Falk W, Straub RH et al. (2007). Adrenal insufficiency and colonic inflammation after a novel chronic psycho-social stress paradigm in mice: implications and mechanisms. Endocrinology 148: 670-682.

Rodgers RJ, Randall JI (1986). Acute non-opioid analgesia in defeated male mice. Physiol Behav 36: 947-950.

Ruipérez MA, García-Palacios A, Botella C (2002). Clinical features and treatment response in social phobia: axis II comorbidity and social phobia subtypes. Psicothema 14: 426-433.

Ruis MA, te Buwalda B, De Boer SF, Meerlo P, Korte SM, Blokhuis $\mathrm{HJ}$ et al (1999). Housing familiar male wildtype rats together reduces the long-term adverse behavioural and physiological effects of social defeat. Psychoneuroendocrinol 24: 285-300.

Rygula R, Abumaria N, Flugge G, Fuchs E, Ruther E, HavemannReinecke U (2005). Anhedonia and motivational deficits in rats: Impact of chronic social stress. Behav Brain Res 162: 127-134.

Schneier FR, Johnson J, Hornig CD, Liebowitz MR, Weissman MM (1992). Social phobia. Comorbidity and morbidity in an epidemiologic sample. Arch Gen Psychiatry 49: 282-288.

Short KR, Maier SF (1993). Stressor controllability, social interaction, and benzodiazepine systems. Pharmacol Biochem Behav 45: 827-835.

Siegmund A, Wotjak CT (2007). A mouse model of posttraumatic stress disorder that distinguishes between conditioned and sensitised fear. J Psychiatr Res 41: 848-860.

Slattery DA, Desrayaud S, Cryan JF (2005). GABAB receptor antagonist-mediated antidepressant-like behavior is serotonindependent. J Pharmacol Exp Ther 312: 290-296.

Slattery DA, Uschold N, Magoni M, Bär J, Popoli M, Neumann ID et al. (2011). Behavioural consequences of two chronic psychosocial stress paradigms: anxiety without depression. Psychoneuroendocrinol; doi:10.1016/j.psyneuen.2011.09.002 (in press).

Stachowicz K, Brañski P, strok;ak K, van der Putten H, Cryan JF, Flor PJ et al. (2008). Selective activation of metabotropic G-protein-coupled glutamate 7 receptor elicits anxiolytic-like effects in mice by modulating GABAergic neurotransmission. Behav Pharmacol 19: 597-603.

Stangier U, Heidenreich T, Schermelleh-Engel K (2006). Safety behaviors and social performance in patients with generalized social phobia. J Cogn Psychoth 20: 17-31.

Talepasand S, Nokani M (2010). Social phobia symptoms: prevalence and sociodemographic correlates. Arch Iran Med 13: $522-527$.

Thoeringer CK, Erhardt A, Sillaber I, Mueller MB, Ohl F, Holsboer F et al. (2010). Long-term anxiolytic and antidepressant-like behavioural effects of tiagabine, a selective GABA transporter-1 (GAT-1) inhibitor, coincide with a decrease in HPA system activity in C57BL/6 mice. J Psychopharmacol 24: 733-743.

Thorndike EL (1933). A proof of the law of effect. Science 77: 173-175.

Thor DH, Wainwright KL, Holloway WR (1982). Persistence of attention to a novel conspecific: some developmental variables in laboratory rats. Develop Psychobiol 15: 1-8.

Van Ameringen MA, Lane RM, Walker JR, Bowen RC, Chokka PR, Goldner E (2001). Sertraline treatment of generalized social phobia: a 20-week, double-blind, placebo-controlled study. Am J Psychiatry 158: 275-281.

Van Dijken HH, Van der Heyden JA, Mos J, Tilders FJ (1992). Inescapable footshocks induce progressive and longlasting behavioural changes in male rats. Physiol Behav 51: 787-794.

White NM (1989). Reward or reinforcement: what's the difference? Neurosci Biobehav Rev 13: 181-186.

Yan HC, Cao X, Das M, Zhu XH, Gao TM (2010). Behavioral animal models of depression. Neurosci Bull 26: 327-337.

Supplementary Information accompanies the paper on the Neuropsychopharmacology website (http://www.nature.com/npp) 